\title{
Anxiety Talking: Does Anxiety Predict Sharing Information About COVID-19?
}

\author{
Ori Cantwell ${ }^{1}$ and Kostadin Kushlev ${ }^{2}$ \\ ${ }^{1}$ Department of Psychology, Wesleyan University \\ ${ }^{2}$ Department of Psychology, Georgetown University
}

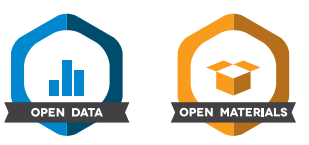

Could anxiety during the early stages of the coronavirus disease (COVID-19) pandemic be linked to greater information sharing about viral threats? To explore whether anxiety may serve as a unique emotional indicator of sharing information in response to COVID-19, we used a representative sample of the United States from the American Trends Panel $(N=9,110)$ conducted April 20th-26th, 2020. Participants reported how they felt in the past week, where they got COVID-19 news from, and whether they had posted COVID-19 news on social media or discussed the pandemic with others. Controlling for other emotions, news sources, and demographic measures, people who felt more anxious were more likely to share information about the coronavirus pandemic on social media and to discuss the pandemic with others, in-person, and online. These findings are consistent with functionalist theories of emotion, which postulate that fear plays a unique role in communication about threats.

Keywords: anxiety, COVID-19, information sharing, social media, news media

Supplemental materials: https://doi.org/10.1037/tmb0000057.supp

The coronavirus disease (COVID-19) pandemic began as a public health emergency in Wuhan, China in late 2019. As the virus spread around the globe throughout 2020 , so did the evidence for its negative effects on both physical and mental health (Gao et al., 2020). Setting aside the serious complications of the disease itself, evidence suggests that just the simple threat of the virus could lead to mental health issues and even neurological changes (Lu et al., 2020). In Wuhan, for example, Chinese citizens who were more exposed to the "infodemic" of public health news on social media were nearly twice as likely to have symptoms of anxiety disorders (Gao et al., 2020).
Another study, which tracked 50 healthy volunteers from pre- to postpandemic, showed increases in the size of the amygdala - a brain region that processes fear and anxiety (Salomon et al., 2021). But is some anxiety during a pandemic necessarily a bad thing?

From an evolutionary perspective, emotions play a functional role in survival (Ekman, 1992; James, 1922; Keltner \& Lerner, 2010). Fear and anxiety, in particular, are elicited in response to perceived threats, driving individuals to avoid threats (Keltner \& Lerner, 2010; Raghunathan et al., 2006; Raghunathan \& Pham, 1999). In social species, fear and anxiety further play a role in group survival by
Action Editor: Nick Bowman was the action editor for this article.

ORCID Ids: Ori Cantwell (iD https://orcid.org/0000-0003-4632-3211; Kostadin Kushlev (iD https://orcid.org/0000-0003-1025-3258.

Acknowledgments: This publication was made possible by support from the Wesleyan University Department of Psychology's Feldman Fund.

Disclosures: We have no known conflicts of interest to disclose.

Competing Interests: We have no competing interests to disclose.

Author Contributions: Ori Cantwell and Kostadin Kushlev contributed to conception and design. Ori Cantwell contributed to acquisition of data. Ori Cantwell, Kostadin Kushlev contributed to analysis and interpretation of data. Ori Cantwell, Kostadin Kushlev drafted and/or revised the article. Ori Cantwell, Kostadin Kushlev approved the submitted version for publication.

Data Availability: All the survey methodology and questionnaires can be found on this paper's project page on the Open Science Framework, https://osf.io/6425d/. The American Trends Panel data that support the findings of this study are available from the Pew Research Center. For the American Trends Panel March 2020 survey dataset, see https://www.pewsocialtrends.org/dataset/covid-19-late-march-2020/. For the American Trends Panel April 2020 survey dataset, see https://www.pewresearch .org/journalism/dataset/covid-19-late-april-2020/.

Open Science Disclosures:

(II) The data are available at https://osf.io/6425d/

The experiment materials are available at https://osf.io/6425d/

Open Access License: This work is licensed under a Creative Commons Attribution-NonCommercial-NoDerivatives 4.0 International License (CC-BY$\mathrm{NC}-\mathrm{ND}$ ). This license permits copying and redistributing the work in any medium or format for noncommercial use provided the original authors and source are credited and a link to the license is included in attribution. No derivative works are permitted under this license.

Contact Information: Correspondence concerning this article should be addressed to Ori Cantwell, Department of Psychology, Wesleyan University, WesBox 90844, 45 Wyllys Avenue, Middletown, CT 06459, United States. Email: ocantwell@wesleyan.edu 
motivating group members to send alarm signals to other group members (Barber, 1994; Gelfand et al., 2016; Richerson et al., 2016). A vervet monkey who sees a leopard, for example, does not only run for its own safety, but also produces an alarm call to alert other members of the group; once alerted, these members of the group further spread the alarm signal (Seyfarth et al., 1980). In this case, the information shared by the first monkey, not the leopard itself, is what triggers the fear response and further information sharing in the rest of the vervet monkeys. In the presence of a threat, then, fear should be associated both with the passive consumption and active sharing of information about the threat (Keltner \& Lerner, 2010; Raghunathan et al., 2006; Raghunathan \& Pham, 1999).

In humans, fear and anxiety are also associated with communication of threats, albeit through much more sophisticated channels of communication (Hauser et al., 2010). In the 21st century, these channels of communication include mass and social media. Thus, passive information consumption about the threat of the coronavirus pandemic via mass and social media should be associated with more fear and anxiety (cf. Kramer et al., 2014). Indeed, exposure to information through both mass and social media during the coronavirus pandemic has been linked to seeing the public health risks of COVID-19 as more severe and with a stronger intention to take protective measures (Lin et al., 2020). During another deadly pandemic - the 2015 Middle East Respiratory Syndrome (MERS-CoV)—exposure to MERS information on social media was associated with greater fear and more preventative behaviors (Oh et al., 2021).

Social media, of course, allows people not only to passively consume information but also to actively spread information. From a functionalist perspective, fear and anxiety should be associated not only with the passive consumption of information but also with the active sharing of information about the coronavirus pandemic. Going beyond past research, we wanted to explore whether anxiety-above and beyond other negative emotions-was associated with sharing information about the pandemic. Indeed, functionalist accounts of emotion postulate that fear and anxiety should predict communication of a threat more so than other negative emotions. In contrast to fear, sadness, for example, is associated with perceptions of helplessness and a tendency to withdraw from others (Lazarus, 1991; Shaver et al., 1987). The main purpose of the present research, therefore, is to explore whether anxiety is a unique emotional indicator of active sharing of information about the coronavirus pandemic.

\section{The Present Research}

To explore whether anxiety may be a unique emotional indicator of information sharing during the COVID-19 pandemic, we used a representative sample of the United States from the American Trends Panel (American Trends Panel, 2020a). Participants were surveyed between April 20th and April 26th, 2020-6 weeks after the U.S. government declared COVID-19 a national emergency. Passive Information Consumption was assessed by measuring how often people consumed information about the coronavirus pandemic via mass and social media. If a person just read posts on their Facebook newsfeed or watched a newscast on TV, this constituted passive information consumption. In contrast, Active Information Sharing was assessed by measuring whether or not people had posted or shared information on social media about the pandemic (active social media sharing) and how often people discussed the coronavirus pandemic with others--whether in the comments of a Twitter thread or face-to-face (interactive information sharing). We first examined the bivariate relationships between feeling anxious, passive information consumption, and active information sharing. Then, we used multiple regression to discern whether anxiety-above and beyond other negative emotions-predicts active and interactive information sharing. In the multiple regression models, we further controlled for demographics that may causally influence both anxiety and information sharing.

\section{Method}

\section{Participants}

Participants were a sample of noninstitutionalized adults residing in the United States $(N=9,110)$ who were members of the American Trends Panel at the time of the survey. Overall, $46.0 \%$ of participants were male, $89.3 \%$ lived in an urban area, $65.6 \%$ had an annual family income over $\$ 50,000$, and $31.7 \%$ considered themselves politically liberal or very liberal. We made an a priori decision to exclude all observations with missing answers for any of our variables. The original sample size was $N=10,139$.

The sample was $69.6 \%$ White (non-Hispanic), $17.0 \%$ Hispanic, 7.6\% Black (non-Hispanic), and 5.8\% other. While the American Trends Panel itself is nationally representative, the sample for this dataset overrepresented White participants, who make up $60.1 \%$ of the U.S. population, and underrepresented Black and Hispanic participants, who respectively make up $13.4 \%$ and $18.5 \%$ of the U.S. population (U.S. Census Bureau, 2019).

Panel participants were recruited through three random-digit-dial surveys and two national address-based random sample surveys, all conducted by the American Trends Panel. On April 20th and 21st, 2020, participants received either an email or SMS invitation to complete the survey. Survey responses were recorded between April 20th and April 26th, 2020. All participants received post-paid incentives ranging from $\$ 5$ to $\$ 20$. Full methodological details are available on the Open Science Framework (OSF): https://osf .io/6425d/.

\section{Measures \\ Emotions}

As a measure of fear and anxiety, participants reported how often, over the past 7 days, they felt "nervous, anxious, or on edge" $(0=$ Rarely or none of the time [less than 1 day], 1 =Some of a little of the time [1-2 days], 2 = Occasionally or a moderate amount of time [34 days] to $3=$ Most or all of the time [5-7 days]). Using the same scale, participants also reported how often they had felt "depressed," "lonely," "hopeful," and "had trouble sleeping" in the past 7 days. In addition to these general measures of emotional state, participants were also asked how often in the past 7 days, they had any physical emotional reactions, such as "sweating, trouble breathing, nausea, or a pounding heart when THINKING about their experience with the coronavirus pandemic." Hereafter, we refer to this variable as Psychosomatic Anxiety. See Table 1 for the means and standard deviations of all measures. 


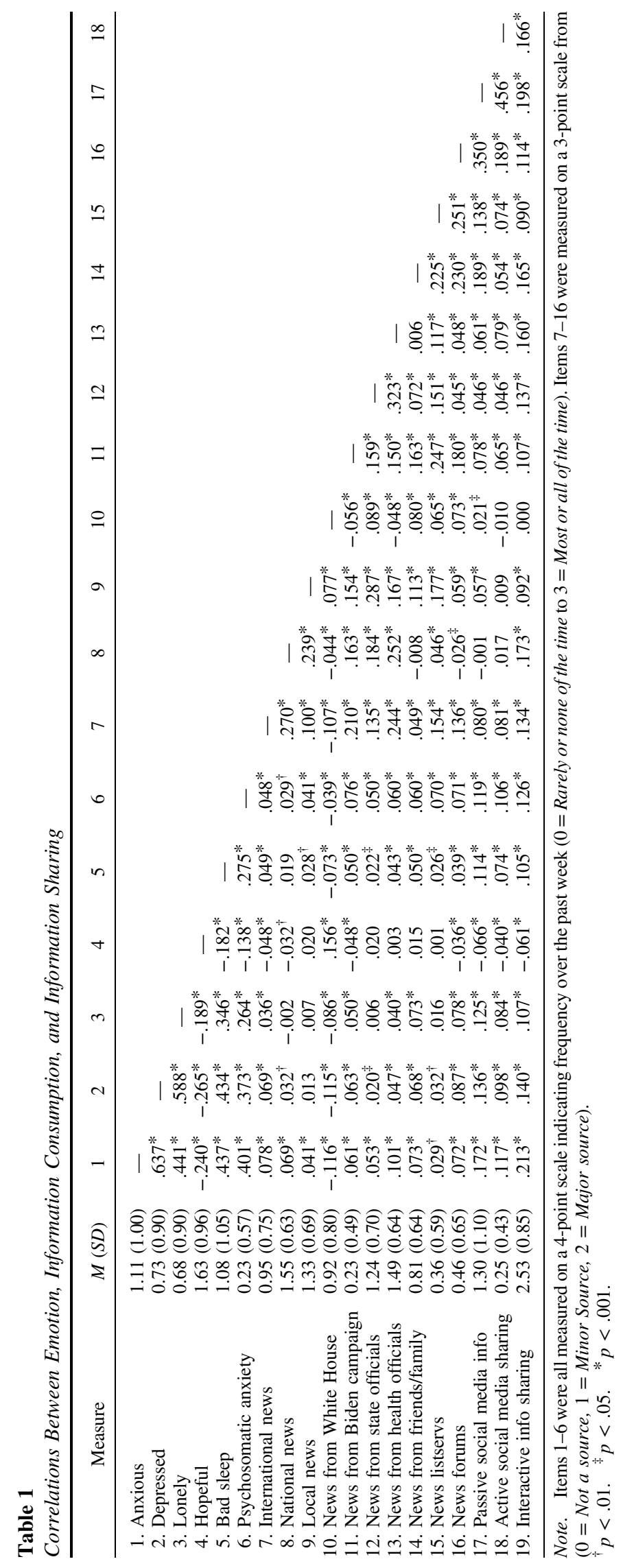




\section{Passive Information Consumption}

As a measure of information consumption about the pandemic on social media (Passive Social Media Info), participants indicated how often ( $0=$ Never, $1=$ Hardly ever, $2=$ Sometimes, $3=$ Often $)$, they got "news and information about the coronavirus outbreak on social media (such as Facebook, Twitter, or Instagram)." As a measure of other sources of information about the pandemic, participants reported "whether each of the following is a source of news for [them] about the coronavirus outbreak" $(0=$ Not a source, $1=$ Minor Source, 2 = Major source): (a) international news outlets; (b) national news outlets; (c) local news outlets; (d) Donald Trump and his coronavirus task force; (e) Joe Biden and his presidential campaign; (f) state and local elected officials and their offices; (g) public health organizations and officials; (h) friends, family, and neighbors; (i) community or neighborhood newsletter or Listserv; and (j) online forums or discussion groups (see Table 1).

\section{Active Information Sharing}

As a measure of active information sharing on social media (Active Social Media Sharing), participants indicated whether $(0-N o ; 1-Y e s)$ they had "posted or shared news and information about the coronavirus outbreak on social media." In addition, as a measure of active information exchange both online and in-person (Interactive Info Sharing), participants reported how often $(0=$ Never, 1 = Hardly ever $;=$ Sometimes, $3=$ Most of the time $; 4=$ All the time) they "are discussing the coronavirus outbreak with others whether online, in person, or over the phone."

\section{Demographics and Controls}

Urban location was coded from county-level Federal Information Processing Standards (FIPS) codes $(0=$ Non-Metropolitan, $1=$ Metropolitan). Sex $(0=$ Female; $1=$ Male $)$, race/ethnicity $($ Black non-Hispanic, White non-Hispanic, Hispanic, and Other), liberal views $(0=$ Very conservative to $4=$ Very liberal $)$, and religious service attendance $(0=$ Never to $5=$ More than once a week $)$ were all self-reported. Participants also reported their education level $(0=$ Less than high school to $5=$ Graduate degree $)$, family income $(0=$ Less than $\$ 10,000$ to $8=\$ 150,000$ or more $)$, and age $(0=18-29$, $1=30-49,2=50-64,3=65+)$. For a full list of survey measures, see https://osf.io/6425d/.

\section{Power and Effect Size}

Very small correlations without any practical significance can become statistically significant in a large sample. Funder and Ozer (2019) suggest that effects of $r<.05$ are unlikely to be of practical significance in most cases. Sensitivity analyses indicated, however, that our sample of 9,110 participants allows us to detect effects as small as $r=.03$ with $80 \%$ power ( $\alpha=.05$, two-tailed). Thus, even when statistically significant, we refrain from interpreting effect sizes, $r$, that are smaller than .05 (Funder \& Ozer, 2019).

\section{Open-Source Tools}

We used the open-source software $R$ ( $R$ Core Team, 2020) and jamovi (Version 1.2; The jamovi project, 2020) to conduct the analysis. The American Trends Panel data that support the findings of this study are available from the Pew Research Center. For the American Trends Panel March 2020 survey dataset, see https://www .pewsocialtrends.org/dataset/covid-19-late-march-2020/. For the American Trends Panel April 2020 survey dataset, see https:// www.pewresearch.org/journalism/dataset/covid-19-late-april-2020/.

\section{Results}

\section{Information Consumption}

Passive consumption of news on social media predicted feeling more anxious, $r=.17,95 \%$ CI [0.15, 0.19], $p<.001$. In fact, consuming information about the pandemic was associated with feeling more anxious across all but one of the information sources: People who got their news about the pandemic from "Donald Trump and his coronavirus taskforce" felt less anxious, $r=-.12,95 \% \mathrm{CI}$ $[-0.10,-0.14], p<.001$ (see Table 1 ). Getting news from President Trump predicted less anxiety $(\beta=-.12, p<.001)$ even after controlling for all other news sources (see Table S1).

\section{Information Sharing}

Consistent with the functionalist theories of fear, people who felt more anxious were more likely to actively share information about the outbreak on social media, $r=.12,95 \%$ CI [0.10, 0.14], $p<.001$, and discuss the pandemic with others, $r=.21,95 \%$ CI $[0.19,0.23]$, $p<.001$ (see Table 1). As shown in Figure 1, people who discussed the pandemic frequently were much more likely to also report feeling anxious than people who rarely discussed the pandemic.

\section{Is Anxiety Uniquely Associated With Information Sharing?}

Anxiety was associated with both consuming and sharing information about the COVID-19 outbreak, but so were other negative emotions, such as feeling depressed or lonely (Table 1). But functionalist accounts of emotion postulate that it should be fear, rather than sadness, that predicts communication of threat about the virus (Lazarus, 1991; Shaver et al., 1987). Thus, we next separately regressed active social media use and interactive information sharing onto feeling anxious, depressed, lonely, and other emotions, as well as a range of other variables including news sources, political orientation, and demographics (Table 2). Even after controlling for all these measures, anxiety continued to predict both actively sharing information on social media $(O R=1.13, p<.001)$ and interactive information sharing $(\beta=.14, p<.001)$. In contrast, feeling depressed (active: $O R=1.00, p>.250$; interactive: $\beta=-.003, p>.250)$ and feeling lonely $(O R=1.04, p>.250$; interactive: $\beta=.02, p=.153)$ did not

We did not include passive consumption of news on social media as a covariate in our regressions (see Table 2). Specifically, Rohrer (2018) cautions against controlling for variables that serve as mediators. Indeed, passive consumption may serve as a mediator between anxiety and active sharing of information: Feeling anxious may drive people to consume more information about the pandemic on social media (cf. Orben et al., 2019), which in turn can lead people to share more information about the pandemic. It is also possible, however, that passive consumption of news on social media causes both feeling more anxiety (Kross et al., 2021) and greater active sharing on social media, making passive consumption a potential confound (Rohrer, 2018). Contrary to this possibility, recent evidence suggests that the 
Figure 1

Relationship Between Different Levels of Anxiety and Interactive Info Sharing

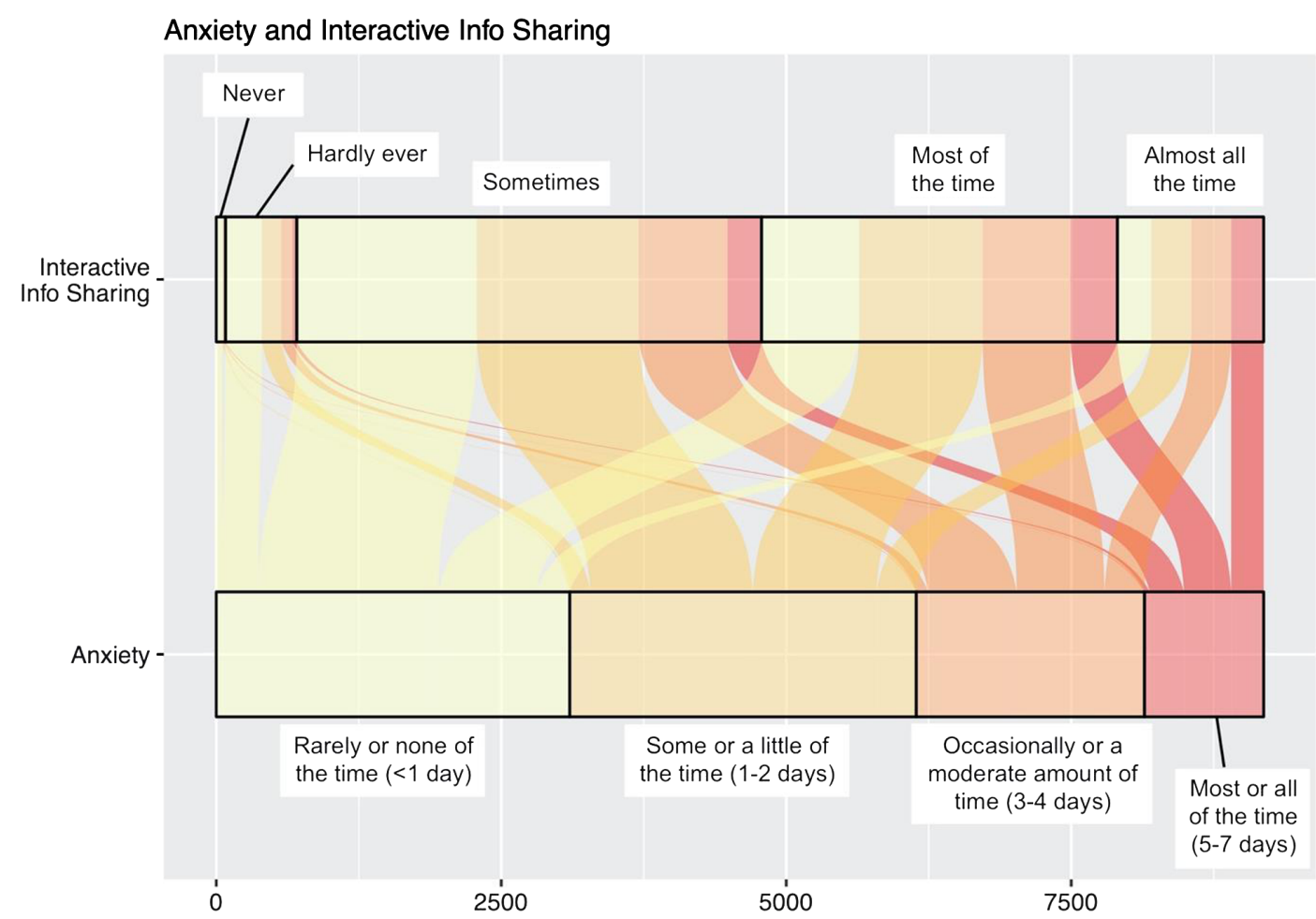

Note. The majority of participants who felt anxious, nervous, or on edge three or more days in the previous week discussed the coronavirus pandemic most or almost all of the time. In contrast, the majority of participants who felt no anxiety or only some anxiety in the previous week discussed the pandemic sometimes or hardly ever. A very small proportion of participants (80 participants, or $0.09 \%$ ) reported that they never discussed the pandemic.

causal impact of passive social media use on negative emotions is tenuous at best (Orben \& Przybylski, 2019; Valkenburg et al., 2021). Still, in supplementary analyses, we added passive news consumption on social media as a covariate in our regression models (see Table S2 in Supplemental Materials).

We found that feeling anxious remained the only emotion that significantly predicted interactive info sharing $(\beta=.13, p<.001)$, but feeling anxious no longer significantly predicted active information sharing on social media $(O R=1.05, p=.189)$. Interestingly, psychosomatic anxiety remained a significant predictor of active sharing on social media $(O R=1.20, p<.001)$. Though passive information consumption of news from social media was a significant predictor of both interactive info sharing $(\beta=.12, p<.001)$ and active social media sharing $(O R=3.16, p=.001)$, the oversized relationship between active and passive social media is notable. Taken together, our pattern of findings across our bivariate analyses and two regression model specifications suggests a stronger and more consistent association of exchanging information about the COVID-19 pandemic with feeling anxious than with feeling sad, depressed, or lonely.

\section{Discussion}

In a large sample of the United States, we found that consuming information about COVID-19 was associated with feeling more anxious. We also found that people who felt more anxious were more likely to actively share information about the pandemic on social media and to discuss the pandemic with others online or inperson. Our findings contribute to a growing literature on the functional role of negative emotions (Forgas, 2013; Kashdan \& Biswas-Diener, 2015). As predicted by such functionalist theories of emotion, we showed that feeling anxious, but not feeling lonely or depressed, was uniquely associated with communicating about a potential threat: the coronavirus pandemic. Although this pattern is consistent with a functional role of anxiety, our correlational data do not allow us to establish a causal role of fear and anxiety in information sharing during the pandemic.

Our use of a publicly available dataset provided us with the opportunity to examine the relationship between anxiety and information sharing in a large cross-section of the U.S. population. These data allowed us to meaningfully control for a range of demographic factors that would not be possible in student or other convenience samples typical in the psychological literature. Still, even in our large sample, Black and Hispanic participants were underrepresented, limiting the generalizability of our findings to those populations. In addition, our use of existing data limited our analyses to the available variables. Thus, for example, we were not able to control for other negative emotions, such as anger, disgust, or guilt. According to the Circumplex Model of Affect (Posner et al., 2005), emotions can be classified along two independent axes: 
Table 2

Anxiety Predicts Interactive and Active Information Sharing Even When Controlling for Other Negative Emotions, News Consumption, and Demographics

\begin{tabular}{|c|c|c|c|c|c|c|c|c|c|c|}
\hline \multirow[b]{2}{*}{ Predictors } & \multicolumn{5}{|c|}{ Interactive info sharing } & \multicolumn{5}{|c|}{ Active info sharing (social media) } \\
\hline & $b$ & $S E$ & $\beta$ & $t$ & $p$ & $b$ & $S E$ & $O R$ & $Z$ & $p$ \\
\hline Intercept & 2.569 & 0.013 & 0.000 & 195.96 & $<.001$ & -1.531 & 0.198 & 0.216 & -7.729 & $<.001$ \\
\hline Anxious & 0.118 & 0.012 & 0.140 & 10.275 & $<.001$ & 0.121 & 0.034 & 1.129 & 3.524 & $<.001$ \\
\hline Depressed & -0.003 & 0.014 & -0.003 & -0.190 & .850 & -0.005 & 0.040 & 0.995 & -0.118 & .906 \\
\hline Lonely & 0.017 & 0.012 & 0.018 & 1.429 & .153 & 0.034 & 0.034 & 1.035 & 1.010 & .312 \\
\hline Hopeful & -0.011 & 0.009 & -0.012 & -1.175 & .240 & -0.010 & 0.028 & 0.990 & -0.369 & .712 \\
\hline Bad sleep & 0.007 & 0.009 & 0.009 & 0.768 & .442 & 0.026 & 0.027 & 1.027 & 0.965 & .335 \\
\hline Psychosomatic anxiety & 0.045 & 0.016 & 0.031 & 2.806 & .005 & 0.164 & 0.045 & 1.179 & 3.671 & $<.001$ \\
\hline International news & 0.052 & 0.012 & 0.047 & 4.326 & $<.001$ & 0.107 & 0.037 & 1.113 & 2.884 & .004 \\
\hline National news & 0.140 & 0.015 & 0.103 & 9.440 & $<.001$ & -0.003 & 0.046 & 0.997 & -0.068 & .945 \\
\hline Local news & 0.006 & 0.013 & 0.005 & 0.462 & .644 & -0.119 & 0.041 & 0.888 & -2.919 & .004 \\
\hline News from White House & 0.067 & 0.012 & 0.064 & 5.551 & $<.001$ & 0.018 & 0.037 & 1.018 & 0.499 & 618 \\
\hline News from Biden campaign & 0.027 & 0.019 & 0.016 & 1.427 & .015 & 0.012 & 0.054 & 1.012 & 0.224 & .823 \\
\hline News from state officials & 0.060 & 0.013 & 0.049 & 4.514 & $<.001$ & 0.072 & 0.040 & 1.075 & 1.786 & .074 \\
\hline News from health officials & 0.080 & 0.015 & 0.060 & 5.495 & $<.001$ & 0.175 & 0.046 & 1.191 & 3.815 & $<.001$ \\
\hline News from friends/family & 0.166 & 0.014 & 0.126 & 12.10 & $<.001$ & -0.010 & 0.042 & 0.99 & -0.248 & .805 \\
\hline News listservs & 0.008 & 0.015 & 0.006 & 0.527 & .589 & 0.038 & 0.045 & 1.039 & 0.844 & .399 \\
\hline News forums & 0.072 & 0.014 & 0.055 & 5.213 & $<.001$ & 0.555 & 0.039 & 1.742 & 14.17 & $<.001$ \\
\hline Urban (v. rural) & 0.053 & 0.027 & 0.020 & 1.957 & .050 & -0.205 & 0.082 & 0.815 & -2.507 & .012 \\
\hline Male (v. female) & -0.085 & 0.017 & -0.050 & -4.915 & $<.001$ & -0.280 & 0.053 & 0.756 & -5.285 & $<.001$ \\
\hline Age & -0.037 & 0.009 & -0.042 & -3.913 & $<.001$ & -0.088 & 0.029 & 0.915 & -3.099 & .002 \\
\hline Education & 0.031 & 0.007 & 0.053 & 4.696 & $<.001$ & 0.002 & 0.020 & 1.002 & 0.105 & .917 \\
\hline Political ideology & 0.040 & 0.010 & 0.051 & 4.031 & $<.001$ & 0.068 & 0.030 & 1.071 & 2.295 & .022 \\
\hline Religiosity & -0.002 & 0.006 & -0.003 & -0.307 & .759 & 0.017 & 0.017 & 1.018 & 1.028 & .304 \\
\hline Family income & 0.030 & 0.004 & 0.081 & 7.134 & $<.001$ & -0.016 & 0.013 & 0.984 & -1.271 & .204 \\
\hline \multicolumn{11}{|c|}{ Race/ethnicity (v. Black non-Hispanic) } \\
\hline White non-Hispanic & -0.203 & 0.203 & -0.241 & -6.070 & $<.001$ & -0.009 & 0.100 & 0.991 & -0.094 & .925 \\
\hline Hispanic & -0.155 & 0.037 & -0.183 & -4.196 & $<.001$ & 0.203 & 0.108 & 1.225 & 1.880 & .060 \\
\hline Other & -0.230 & 0.047 & -0.272 & -4.933 & $<.001$ & -0.040 & 0.139 & 0.961 & -0.287 & .774 \\
\hline
\end{tabular}

Note. Urban location was coded from county-level FIPS codes $(0=$ Non-Metropolitan; 1 = Metropolitan $)$. Political ideology was self-reported on a scale from $0=$ Very conservative to $4=$ Very liberal). We found no evidence of multicollinearity between predictors (see Table S3). See Figure S1 for further diagnostics.

positive-negative and high-arousal-low-arousal. Feeling fearful or anxious constitute high-arousal negative affect, whereas feeling depressed and lonely constitute low-arousal negative affect. Thus, our models only controlled for low-arousal negative emotions when examining the relationship between feeling anxious and information sharing. It may, therefore, be that any other higharousal negative emotions, such as anger, would also be associated with more information sharing (cf, Oh et al., 2021). This is an important area for future research.

The variables available in our public dataset also did not allow us to examine whether that information was accurate or to distinguish the quality of an information source. Thus, misinformation, rather than correct information about the pandemic, may be what explains the positive association between information consumption and anxiety. We speculate, however, that the pattern of relationships we observed is, at least in part, inconsistent with this possibility. Specifically, we found that consuming information about the pandemic through most sources was associated with feeling more anxious. In contrast, people who got their coronavirus news from President Donald Trump were less anxious. We speculate that this pattern of results may be due to President Trump's attempt to minimize the danger of the pandemic. Although he privately recognized the real threat of the coronavirus (Woodward, 2020), President Trump publicly minimized the threat of the virus to "avoid panic" (U.S. White House, 2020a, 2020b, 2020c, 2020 d). Further research is needed to explore how information, misinformation, and disinformation relate to fear and anxiety in the context of a public health threat.

As our theorizing is based on functionalist theories of emotion, we have implicitly suggested that anxiety may play an adaptive role during the coronavirus pandemic to the extent that it is associated with greater information sharing about the pandemic. Past research does suggest that accurate information about health threats is associated with more proximate adaptive behaviors, such as taking health-protective measures (Beck \& Frankel, 1981; Leventhal, 1970; Lin et al., 2020; Oh et al., 2021). Because our data did not allow us to examine the accuracy of the information people shared or discussed about the pandemic; however, we could have observed a maladaptive association between anxiety and spreading misinformation. For example, people who were more anxious could have been more likely to share information about government conspiracies or against health-protective behaviors, such as social distancing. If this is the case, then anxiety should be associated with more information sharing but less social distancing. In our supplementary analyses, however, we found evidence inconsistent with this possibility. Though social distancing was not measured in the April 2020 survey of the American Trends Panel used in the present research, social distancing was measured in the March 2020 survey 
(American Trends Panel, 2020b). Our analyses of the March 2020 data show that people who felt more anxious were more likely to practice social distancing (see Table S4). Still, future research should examine more directly the connection between anxiety, information sharing, and adaptive health-protective behaviors.

\section{References}

American Trends Panel. (2020a). COVID-19 late April 2020 (ATP wave 66) [Data set]. Pew Research Center. https://www.pewresearch.org/journa lism/dataset/covid-19-late-april-2020/

American Trends Panel. (2020b). COVID-19 late March 2020 (ATP wave 64) [Data set]. Pew Research Center. https://www.pewsocialtrends.org/da taset/covid-19-late-march-2020/

Barber, N. (1994). Machiavellianism and altruism: Effect of relatedness of target person on machiavellian and helping attitudes. Psychological Reports, 75(1), 403-422. https://doi.org/10.2466/pr0.1994.75.1.403

Beck, K. H., \& Frankel, A. (1981). A conceptualization of threat communications and protective health behavior. Social Psychology Quarterly, 44(3), 204-217. https://doi.org/10.2307/3033834

Ekman, P. (1992). An argument for basic emotions. Cognition and Emotion, 6(3-4), 169-200. https://doi.org/10.1080/02699939208411068

Forgas, J. P. (2013). Don't worry, be sad! On the cognitive, motivational, and interpersonal benefits of negative mood. Current Directions in Psychological Science, 22(3), 225-232. https://doi.org/10.1177/0963721412474458

Funder, D. C., \& Ozer, D. J. (2019). Evaluating effect size in psychological research: Sense and nonsense. Advances in Methods and Practices in Psychological Science, 2(2), 156-168. https://doi.org/10.1177/25152459 19847202

Gao, J., Zheng, P., Jia, Y., Chen, H., Mao, Y., Chen, S., Wang, Y., Fu, H., \& Dai, J. (2020). Mental health problems and social media exposure during COVID-19 outbreak. PLOS ONE, 15(4), Article e0231924. https:// doi.org/10.1371/journal.pone.0231924

Gelfand, M. J., Roos, P., Nau, D., Harrington, J., Mu, Y., \& Jackson, J. (2016). Societal threat as a moderator of cultural group selection. Behavioral and Brain Sciences, 39, Article e38. https://doi.org/10.1017/ S0140525X15000114

Hauser, M. D., Chomsky, N., \& Fitch, W. T. (2010). The faculty of language: What is it, who has it, and how did it evolve? In R. K. Larson, V. Deprez, \& H. Yamakido (Eds.), The evolution of human language (pp. 14-42). Cambridge University Press. https://doi.org/10.1017/CBO978051181 7755.002

James, W. (1922). The emotions. In C. G. Lange \& W. James (Eds.), The emotions (Vol. 1, pp. 93-135). Williams \& Wilkins. https://doi.org/10 $.1037 / 10735-003$

Kashdan, T., \& Biswas-Diener, R. (2015). The upside of your dark side: Why being your whole self_not just your "good" self_drives success and fulfillment. Penguin.

Keltner, D., \& Lerner, J. S. (2010). Emotion. In S. T. Fiske, D. T. Gilbert, \& G. Lindzey (Eds.), Handbook of social psychology (pp. 317-352). Wiley. https://doi.org/10.1002/9780470561119.socpsy001009

Kramer, A. D. I., Guillory, J. E., \& Hancock, J. T. (2014). Experimental evidence of massive-scale emotional contagion through social networks. Proceedings of the National Academy of Sciences of the United States of America, 111(24), 8788-8790. https://doi.org/10.1073/pnas.1320040111

Kross, E., Verduyn, P., Sheppes, G., Costello, C. K., Jonides, J., \& Ybarra, O. (2021). Social media and well-being: Pitfalls, progress, and next steps. Trends in Cognitive Sciences, 25(1), 55-66. https://doi.org/10.1016/j.tics 2020.10.005

Lazarus, R. S. (1991). Progress on a cognitive-motivational-relational theory of emotion. American Psychologist, 46(8), 819-834. https://doi.org/10 $.1037 / 0003-066$ X.46.8.819
Leventhal, H. (1970). Findings and theory in the study of fear communications. Advances in Experimental Social Psychology, 5, 119-186. https:// doi.org/10.1016/S0065-2601(08)60091-X

Lin, Y., Hu, Z., Alias, H., \& Wong, L. P. (2020). Impact of mass and social media on psychobehavioral responses to COVID-19: A survey of medical university students in Fujian, China during the downward trend of COVID-19. Journal of Medical Internet Research, 22(7), Article e19982. https://doi.org/10.2196/19982

Lu, Y., Li, X., Geng, D., Mei, N., Wu, P. Y., Huang, C. C., Jia, T., Zhao, Y., Wang, D., Xiao, A., \& Yin, B. (2020). Cerebral micro-structural changes in COVID-19 patients-an MRI-based 3-month follow-up study. EClinicalMedicine, 25(2), Article 100484. https://doi.org/10.1016/j.eclinm .2020 .100484

Oh, S. H., Lee, S. Y., \& Han, C. (2021). The effects of social media use on preventive behaviors during Infectious disease outbreaks: The mediating role of self-relevant emotions and public risk perception. Health Communication, 36(8), 972-981. https://doi.org/10.1080/10410236.2020.1724639

Orben, A., Dienlin, T., \& Przybylski, A. K. (2019). Social media's enduring effect on adolescent life satisfaction. Proceedings of the National Academy of Sciences of the United States of America, 116(21), 10226-10228. https://doi.org/10.1073/pnas.1902058116

Orben, A., \& Przybylski, A. K. (2019). The association between adolescent well-being and digital technology use. Nature Human Behaviour, 3(2), 173-182. https://doi.org/10.1038/s41562-018-0506-1

Posner, J., Russell, J. A., \& Peterson, B. S. (2005). The circumplex model of affect: An integrative approach to affective neuroscience, cognitive development, and psychopathology. Development and Psychopathology, 17(3), 715-734. https://doi.org/10.1017/S0954579405050340

Raghunathan, R., \& Pham, M. T. (1999). All negative moods are not equal: Motivational influences of anxiety and sadness on decision making. Organizational Behavior and Human Decision Processes, 79(1), 5677. https://doi.org/10.1006/obhd.1999.2838

Raghunathan, R., Pham, M. T., \& Corfman, K. P. (2006). Informational properties of anxiety and sadness, and displaced coping. The Journal of Consumer Research, 32(4), 596-601. https://doi.org/10.1086/500491

$\mathrm{R}$ Core Team. (2020). R: A language and environment for statistical computing [Computer software]. https://www.R-project.org/

Richerson, P., Baldini, R., Bell, A. V., Demps, K., Frost, K., Hillis, V., Mathew, S., Newton, E. K., Naar, N., Newson, L., Ross, C., Smaldino, P. E., Waring, T. M., \& Zefferman, M. (2016). Cultural group selection plays an essential role in explaining human cooperation: A sketch of the evidence. Behavioral and Brain Sciences, 39, Article e30. https://doi.org/ 10.1017/S0140525X1400106X

Rohrer, J. M. (2018). Thinking clearly about correlations and causation: Graphical causal models for observational data. Advances in Methods and Practices in Psychological Science, 1(1), 27-42. https://doi.org/10.1177/ 2515245917745629

Salomon, T., Cohen, A., Barazany, D., Ben-Zvi, G., Botvinik-Nezer, R., Gera, R., Oren, S., Roll, D., Rozic, G., Saliy, A., Tik, N., Tsarfati, G., Tavor, I., Schonberg, T., \& Assaf, Y. (2021). Brain volumetric changes in the general population following the COVID-19 outbreak and lockdown. NeuroImage, 239, Article 118311. https://doi.org/10.1016/j.neuroimage .2021 .118311

Seyfarth, R. M., Cheney, D. L., \& Marler, P. (1980). Monkey responses to three different alarm calls: Evidence of predator classification and semantic communication. Science, 210(4471), 801-803. https://doi.org/10.1126/ science.7433999

Shaver, P., Schwartz, J., Kirson, D., \& O'Connor, C. (1987). Emotion knowledge: Further exploration of a prototype approach. Journal of Personality and Social Psychology, 52(6), 1061-1086. https://doi.org/ 10.1037/0022-3514.52.6.1061

The jamovi project. (2020). jamovi (Version 1.2) [Computer Software]. https://www.jamovi.org 
U.S. Census Bureau. (2019). Quick facts: United States. Retrieved March 19, 2021, from https://www.census.gov/quickfacts/fact/table/US/PST045219

U.S. White House. (2020a, February 27). Remarks by President Trump, Vice President Pence, and members of the coronavirus task force in press conference [Interview transcript]. https://trumpwhitehouse.archives.gov/ briefings-statements/remarks-president-trump-vice-president-pence-memberscoronavirus-task-force-press-conference/

U.S. White House. (2020b, March 7). Remarks by President Trump after tour of the centers for disease control and prevention|Atlanta, GA [Interview transcript]. https://trumpwhitehouse.archives.gov/briefings-statements/ remarks-president-trump-tour-centers-disease-control-prevention-atla nta-ga/

U.S. White House. (2020c, March 10). Remarks by President Trump after meeting with republican senators [Interview transcript]. https://trumpwhitehouse archives.gov/briefings-statements/remarks-president-trump-meetingrepublican-senators-2/
U.S. White House. (2020d, April 3). Remarks by President Trump, Vice President Pence, and members of the coronavirus task force in press conference [Interview transcript]. https://trumpwhitehouse.archives.gov/ briefings-statements/remarks-president-trump-vice-president-pence-memberscoronavirus-task-force-press-briefing-18/

Valkenburg, P. M., Beyens, I., Pouwels, J. L., van Driel, I. I., \& Keijsers, L. (2021). Social media browsing and adolescent well-being: Challenging the "passive social media use hypothesis." Journal of Computer-Mediated Communication. Advance online publication. https://doi.org/10.1093/ jcmc/zmab015

Woodward, B. (2020). Rage. Simon \& Schuster.

Received April 5, 2021

Revision received September 22, 2021 Accepted September 26, 2021 